\title{
Controlling in Manufacturing Enterprises Operating in the Territory of the Slovak Republic
}

\author{
Vladislav Sochanič ${ }^{1, *}$, Paulína Paprskárová ${ }^{1}$ \\ ${ }^{1}$ Faculty of Business Management, University of Economics in Bratislava, Faculty of Business \\ Management, Department of Management, Dolnozemská Cesta 1/b, 85235 Bratislava, Slovak \\ Republic
}

\begin{abstract}
In recent years, control has become increasingly important than the last management function. The growing interest in this function is also due to the economic crisis, which has led many companies to be on the verge of bankruptcy or to force their business to cease completely. Companies that wanted to survive in a turbulent business environment were forced to streamline processes as well as redistribute their resources more efficiently. The main aim of the paper is to find out the importance of control perceived by employees and managers and the introduced changes in control in manufacturing companies in the Slovak Republic.
\end{abstract}

\section{Introduction}

In today's business environment, businesses should be constantly improving, working to increase competitive advantage and adapting constantly to market and customer needs. The aim of the company is to achieve specific results in a specific period and maximize the current value of the company. In order for managers to take the right measures to help them achieve their business goals, they need to know the individual processes in the business and their parts. Control focuses on identifying individual parts of business processes, their analysis and performance measurement and subsequent comparison of measured and planned values. If the process does not deliver planned results, the manager takes corrective action. Through continuous control, the company can continuously improve and streamline the company's business processes. However, the right measure must be found between exaggerated and ineffective control and lack of control or its absence. Understanding current changes and trends in internal control can help businesses adapt to the business environment and gain or maintain their competitive advantage.

\section{Theoretical background}

Manufacturing is a constantly evolving industry that needs to be sufficiently competitive and adaptable to market changes. For this reason, production and management

\footnotetext{
*Corresponding author: vladislav.sochanic@euba.sk, paulina.paprskarova@euba.sk
} 
have to be seen as a means of making production more efficient and more flexible for the market and conditions in it.

Production management deals with complex management not only of production, but also pre-production and post-production stages or logistics itself. According to Leščišin et al. (2008) it is necessary to put the focus on the management of the whole production system, which should direct all tangible and intangible processes in the company - development, design and other pre-production activities, production processes and post-production services.

Thanks to control and controlling, it is possible to improve individual business processes and make their results more effective, which can be a major competitive advantage of the company. For example, ISO concepts, quality management or Total Quality Management (TQM) and Kaizen are also based on continual improvement and improvement of currently applied processes, which reduces costs, increases efficiency or brings greater benefits to the process. As Merchant (1998) states, there may be significant problems in checking if an incorrect control deals with wrong objects. Managers must be able to recognize these problems and take corrective action.

Therefore, top management's view of control should include a greater dispersion of factors, according to Horovitz and Webb (2015):

$>$ the degree of detail found in the inspection,

$>$ frequency of control,

$>$ degree of control formalization,

$>$ the degree of centralization of control,

$>$ degree of sophistication of control,

$>$ emphasis on control and its outputs towards top management.

The management levels have the above-mentioned factors at different levels of managers. For example, top managers generally do not carry out detailed employee checks at line level. Bates et al. (2005) define top management as a relatively small group of people who is responsible for general management tasks and performs strategic planning for the enterprise, takes responsibility for the direction of business and sets long-term goals and tasks for the enterprise. It constantly monitors the business environment and sets the vision and future direction of company. Middle management has the task of managing specific functional areas, often a larger group of people than in top management. The middle management implements the decisions of the top management and is responsible for the mid-term planning of the company. It transforms strategies from top management to sub-goals and action plans for lower levels of management. It monitors the business environment that affects the functional area. Managers of first line typically control small segments in a specific department or function. They are focused on the fulfillment of daily tasks and short-term goals assigned to higher levels of management. 


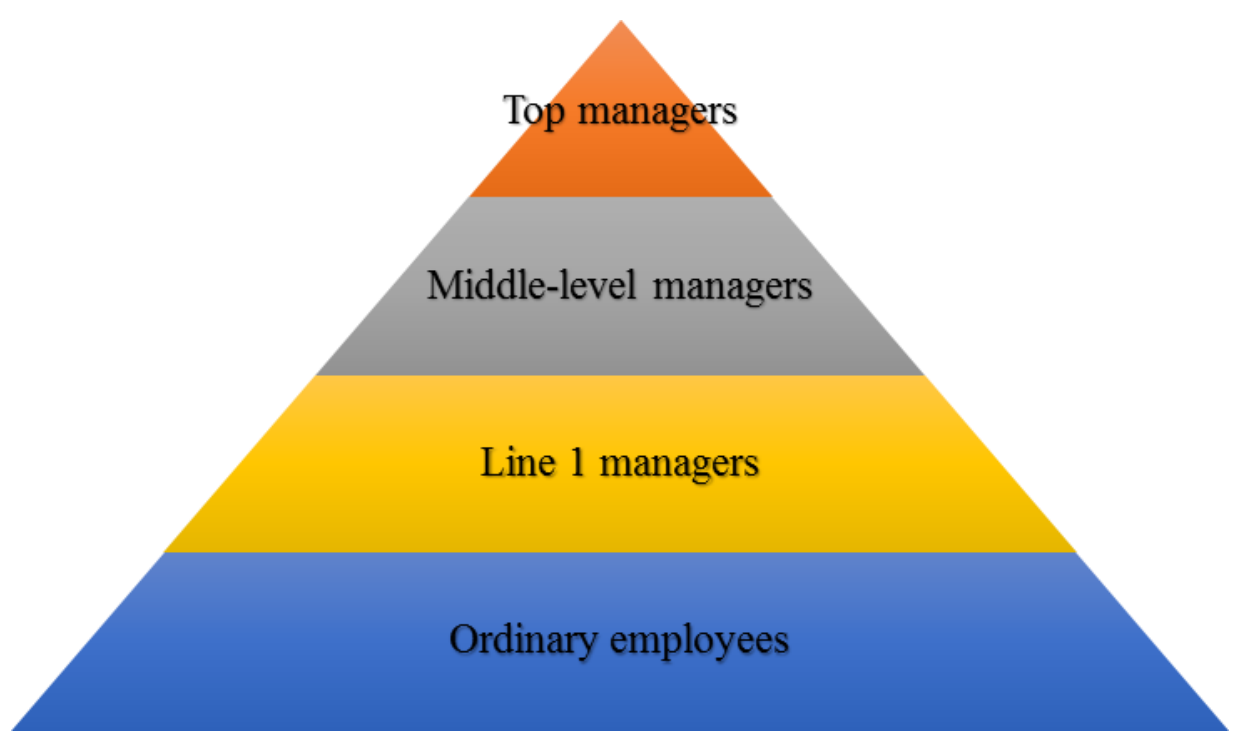

Fig. 1. Levels of management by Robbins and Coulter

Source: ROBBINS S. P., COULTER M. (2012). Management. p. 6

\section{Materials and methods}

The main aim of the paper is to find out the importance of control perceived by employees and managers and the introduced changes in control in manufacturing companies in the Slovak Republic.

Scientific methods such as analysis, synthesis, induction, deduction, abstraction, comparison and generalization were used.

The survey data were collected between autumn 2018 and spring 2019 using a questionnaire created in google forms. The questions in the questionnaire were formulated on the basis of previous research and expert interviews. The rating scale was set from 1 to 6 to avoid mean values. Overall research was not only focused on business units operating in manufacturing sectors, but also on businesses operating in other industries. Altogether 462 questionnaires were collected, of which 70 companies are active in the manufacturing sector. For the purposes of this article, only selected research enterprises operating in the manufacturing sectors have been analysed. The object of the investigation is business units operating in manufacturing industries as defined by NACE operating in the territory of the Slovak Republic. The subject of investigation is control, its importance and intensity, as well as changes in control.

The research sample contains 70 respondents, the first question concerned the level of management of respondents' job positions in selected enterprises, which is also divided in Figure 1. The respondents are:

$>42.85 \%$ top managers,

$>21.42 \%$ mid-level managers

$>12.85 \% 1$ st line managers

$>22.88 \%$ non-managerial workers (economist, controller or accountant). 


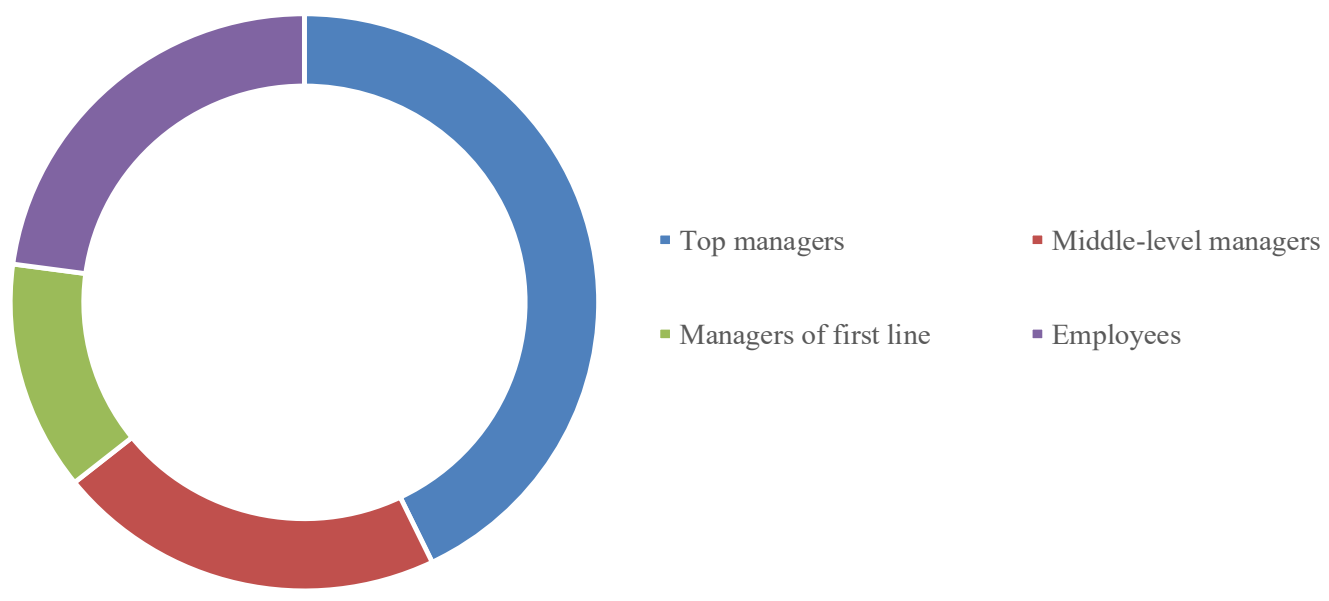

Fig. 2. Levels of managers

Source: Own work

The average number of years which managers have worked in individual positions in chosen businesses was 12.43 years for top managers, 9.64 years for middle managers, 11.66 years for first-line managers and 12.33 years for non-managers. The average number of years managers have worked at each level of management was found mainly in addition to qualitative answers, as the overview of business processes and control is usually given to higher managers who work in the company or in a given position for a longer period of time.

Generally, the manufacturing enterprises had the legal form of a limited liability company (53 enterprises), the second most frequently represented legal form was a jointstock company (13 enterprises) and the rest of the enterprises were a cooperative and selfemployed persons. Figure 2 shows respondents in regions of Slovakia. Most of them were from Trenčín, Trnava and Bratislava regions. The Košice Region was the least represented. Data were taken from portal finstat.sk. 


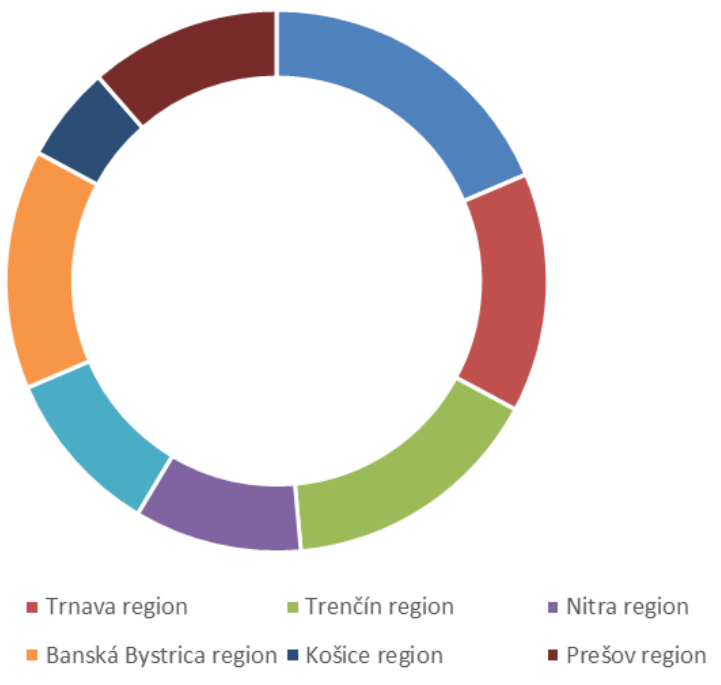

Fig. 3. Respondents by region

Source: Own work

\section{Research and discussion}

The identification questions were followed by a question on the importance that respondents attach to control. The rating scale was determined from 1 (not important) to 6 (very important). The average assigned value was 5.34 (arithmetic mean: $\mu=$ 5.34285714286; absolute deviation: 55.2; average deviation: 0.788571428571 ; variance: 0.968163265306 ; standard deviation $\sigma=0.983952877584$ ). Figure 4 shows the average values assigned by respondents at each management level.

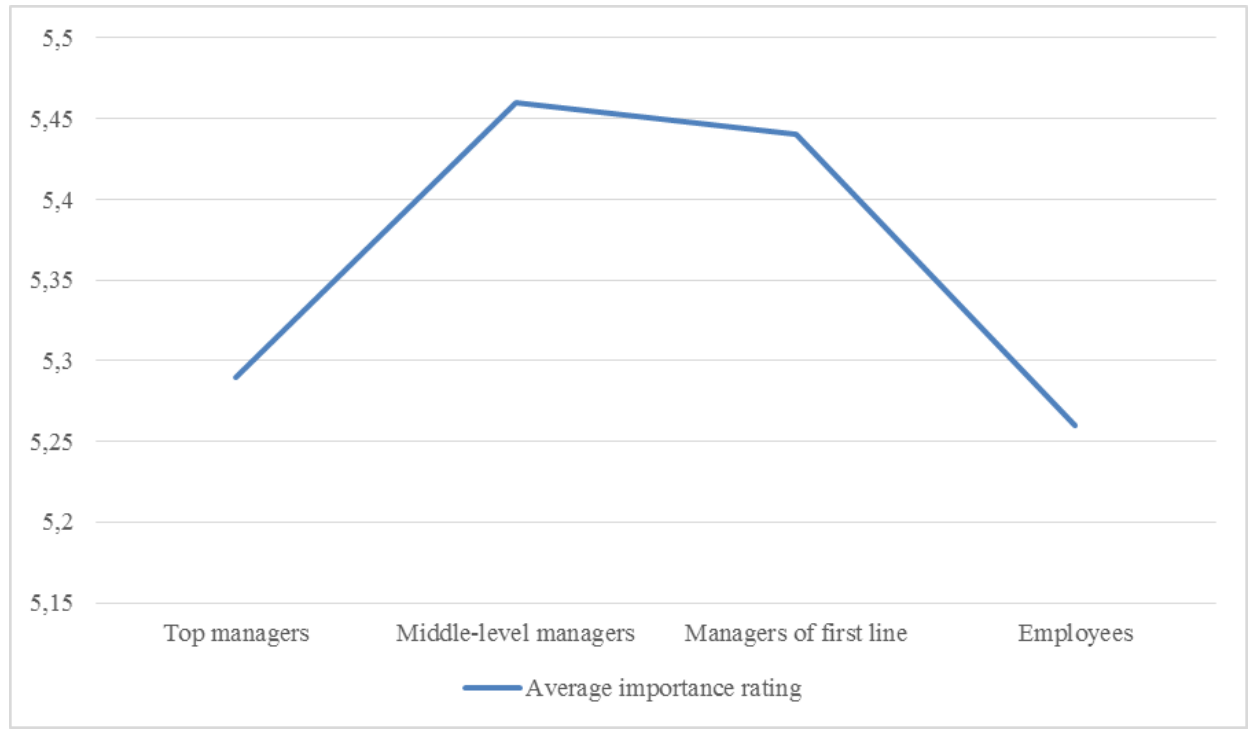

Fig. 4. Average values added to importance of control by managers and non-managers

Source: Own work 
After assigning a score on the rating scale, another question was aimed at justifying the respondent's attitude. This was therefore a justification given to the importance of control. The lowest value (minimum: 2) was reported in two cases by the business director and the financial director. In one case, it was justified that properly set standards and procedures do not require extensive controls. In the second case, it was a company in extinction, where both internal and external controls were almost negligible compared to controls in previous stages of the company's life cycle. Maximum values (maximum: 6) were reported by up to 42 respondents. Most frequently, respondents stated:

$>$ eliminate or minimize errors in selected business processes,

$>$ preventing errors and mistakes,

$>$ prevention of penalties and fines,

$>$ increase efficiency or quality of selected business processes,

$>$ awareness and truthfulness of information obtained through control,

$>$ development of the company and economic prosperity of the company.

On average, scores of 3 and 4 justified that the company has stable employees who do not require a high degree of control, a low number of employees in the company, or claiming that excessive control also carries negatives, so it does not give it excessive importance.

Subsequently, we investigated whether the importance that managers and employees attach to control also reflected the introduction of changes in selected manufacturing companies and what changes they were and how often they reviewed the effectiveness of the inspection process and the need to introduce changes therein.

Up to 11 respondents stated that they review the review process itself and re-evaluate its benefits as a rule at shorter intervals than once a month. It should be noted, however, that in these cases it was a control of parts of the control process, not the overall control process. At the same time, all respondents had the power to change the review process and introduce changes. A further 12 respondents said they reviewed the review process once a month and two of the respondents had the power to change only some parts of the review process. The rest of the respondents (10) could interfere with the entire control process. Once a quarter, up to 17 respondents review the effectiveness of the review process, of which 7 have the right to change only some parts of the review process, and 10 respondents can introduce changes to all parts of the review process. 21 respondents review the review process once a year, of which 12 can only introduce changes to some parts of the review process, 6 respondents can change all parts of the review process, and 3 have no authority to change anything in the review process. At more than one year intervals, the review process is reviewed by 9 respondents, while only 3 of them can introduce changes to the review process and other respondents have no authority to do so.

Another question was aimed at identifying specific changes that have been made to the review process over the past year. Of the respondents, 19 reported that no changes in their control processes had been implemented in their company over the past year. The rest of the respondents (51) reported that they had made several changes to the review process over the past year. A frequent reason was the introduction of changes due to legislative changes, changes in standards or the introduction of changes due to the increasing intensity of external control (financial administration, other audit bodies), which identified shortcomings in current business processes and their control. At the same time, some changes in the inspection, in particular the intensity of the inspection or the change of the inspected object, were introduced to prevent fines and penalties. Another common reason for introducing changes was technological changes in production and automation. For this reason, the review processes were either re-created or designed, or changes were incorporated into the current review process. The last of the reasons were employees and their turnover or lack of qualifications. Respondents reported that there is a lack of skilled 
labor in the current labor market, often shifting between employers. For this reason, it is necessary to constantly train new employees and constantly intensify their monitoring in order to maintain the quality of business processes at the required level.

\section{Conclusion}

Managers and employees attach great importance to auditing in general. This is to a certain extent also due to the high quality requirements of the companies operating in the manufacturing sector. Around three quarters of the enterprises surveyed have introduced changes in the review process in the last year. The main reasons were legislative changes, increasing control intensity from external institutions, changes in technology and robotization.

The specifics of the current state of the labor market and the high demand for qualified employees in manufacturing industries in the Slovak Republic are causing changes in control processes in manufacturing companies. Managers are forced to increase the intensity of control of such employees in order to maintain or increase the quality of individual production processes in companies.

\section{References}

1. B. Bates et al. Business Management: fresh perspectives. (2005)

2. J.H. Horowitz, P. Webb. Top Management Control in Europe. (1980)

3. M. Leščišin et al. Manažement výroby. (2008)

4. K.A. Merchant. Modern management control systems: Text and cases. (1998)

5. S. P. Robbins, M. Coulter. Management, (2003) 